\title{
PRÓPOLIS NO CONTROLE DA MASTITE BOVINA
}

\author{
Erika Cosendey Toledo Mello Peixoto ${ }^{1}$, Julia Gazzoni Jardim, ${ }^{2}$ Eduardo Luiz \\ Heinzen $^{3}$, Paulo Francisco Domingues ${ }^{4}$, Carlos Roberto Padovani ${ }^{4}$, Ricardo de \\ Oliveira Orsi ${ }^{4}$
}

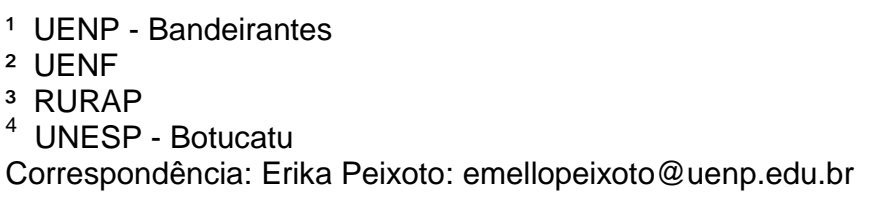

\begin{abstract}
RESUMO: Mastite bovina é considerada a principal doença causadora de grandes perdas econômicas nos rebanhos leiteiros. Usualmente é tratada por antimicrobianos químicos, que promovem resistência farmacológica, resíduos no alimento e contaminação ambiental. Entretanto, o consumidor em diferentes países exige cada vez mais alimentos naturais e de melhor qualidade. Dessa forma, objetivou-se verificar as atividades da própolis no controle de mastite bovina. Foram utilizadas 72 fêmeas Holandesas, avaliadas pelo Teste de Tamis, Califórnia Mastite Teste, contagem de células somáticas e exame microbiológico do leite. Quatro tratamentos foram realizados, sendo Grupo EAP1: $10 \mathrm{~mL}$ de extrato alcoólico de própolis (EAP) a $30 \%$, via oral, durante sete dias consecutivos; Grupo EAP2: além do procedimento descrito para Grupo EAP1, utilizou-se o EAP na imersão dos tetos antes e após a ordenha; Grupo CA: utilizou-se álcool de cereais na imersão dos tetos antes e após a ordenha; e Grupo CT: os animais controle-testemunha foram submetidos aos procedimentos rotineiramente empregados pela propriedade. Os resultados foram analisados por técnica de variância não paramétrica para modelo de medidas repetidas em grupos independentes complementada por comparações múltiplas. Observou-se diminuição na contagem de células somáticas em todos os grupos avaliados. As atividades biológicas da própolis propiciam grandes perspectivas, entretanto, para as condições avaliadas, não foi possível observar diferença entre os tratamentos. Alta diversidade em sua composição química, além da complexidade dos múltiplos mecanismos sinérgicos envolvidos em suas atividades biológicas, exige adicionais ensaios clínicos a fim de se determinar a terapêutica capaz de demonstrar seus benefícios "in vivo".
\end{abstract}

Palavras-chave: agroecologia; bioterapias; leite; produção orgânica

\section{PROPOLIS IN THE CONTROL OF BOVINE MASTITIS}

ABSTRACT: Bovine mastitis is considered the main disease causing great economic losses in dairy herds. It is usually treated by antimicrobial chemicals that promote drug resistance, residues in food and environmental contamination. However, consumers in different countries requires more natural foods and with higher quality. Thus, the objective was to check the activities of propolis in controlling bovine mastitis. Seventy-two Holstein cows were used. The mastitis was identified by the California Mastitis Test, somatic cell counts and microbiological examination of milk. Four treatments were held: in group EAP1 $10 \mathrm{ml}$ of a $30 \%$ alcoholic propolis extract (EAP) were given orally for seven consecutive days; in group EAP2 the same procedure described for the first group was used, in addition EAP was used for immersion of the teats before and after milking; in group CA alcohol was used for immersion of the teats before and after milking; and in group CT animals were subjected to soaking and disinfection, procedures routinely used by the property. The results were analyzed by the non-parametric variance model for repeated measures complemented by independent groups in multiple comparisons. There was a decrease of the somatic cell count in all groups. The biological activities of propolis provide great prospects; however, under the conditions evaluated, it was not possible to observe differences between treatments. The great diversity in its chemical composition and the complexity of multiple synergistic mechanisms involved in its biological activity require additional clinical trials.

Key Words: agroecology; biotherapies; milk; organic production 


\section{INTRODUÇÃO}

Mudanças nos conceitos de produção exigem que o alimento seja produzido em condições higiênicas, por animais sadios e que não estejam eliminando resíduos de antibióticos ou de outras drogas.

A fim de garantir produtos de melhor qualidade, a instrução normativa 51 (Brasil, 2002), regulariza a produção, transporte e venda do leite, padronizando parâmetros de identidade, qualidade, além de proibir a presença de resíduos de antibióticos.

A mastite bovina por sua vez, compromete a qualidade do leite pelo risco de veiculação de agentes patogênicos, além de diminuir a produção. Caracteriza-se por enfermidade multifatorial, de difícil controle e erradicação. Quanto mais precocemente for detectada e tratada, maiores chances de recuperação e menores chances de proliferação e contágio entre os animais existirão. Entretanto, o uso de antibioticoterapia durante a lactação é pouco frequente entre os produtores, principalmente pela baixa eficácia e necessidade de descarte do leite.

Ao longo da história, o homem aprendeu a utilizar produtos naturais e um dos mais utilizados tem sido a própolis. Material resinoso, balsâmico, coletado pelas abelhas dos ramos, flores, pólen, brotos e exsudatos de árvores, a própolis tem sido utilizada no tratamento de enfermidades tanto na medicina humana como na veterinária (Coelho et al., 2010). Sua atividade antibacteriana (Araujo e Marcucci, 2011, Barbosa et al., 2009), antifúngica (Borges et al., 2009; Özdemir et al., 2010), anti-inflamatória e imunoestimulante (Barbosa et al., 2009; Fischer, 2010) são particularmente importantes para terapêutica da mastite. Seu efeito foi testado em agentes causadores de mastite bacteriana
(Loguercio et al., 2006; Andrade, 2010; Saeki et al. 2011), fúngica (Langoni et al., 1996), e sobre outros agentes como algas do gênero Prototheca (Langoni et al., 1995).

Sua ação terapêutica tem sido atribuída aos compostos fenólicos e flavonóides (Bezerra e Gonçalves, 2008), sendo esses últimos ainda relacionados à ação antioxidante, minimizando a peroxidação lipídica e efeito sobre radicais livres (Cabral et al., 2009). Porém, a despeito de diversos estudos comprovarem as propriedades farmacológicas da própolis, a maioria ocorreu em condições controladas, geralmente em animais de laboratório. Assim, há necessidade de realizar ensaios clínicos capazes de determinar dosagem terapêutica e seu real efeito in vivo (Loguercio et al., 2006). Portanto, o objetivo do presente estudo foi avaliar as atividades terapêuticas da própolis no controle da mastite bovina.

\section{MATERIAL E MÉTODOS}

Foram utilizadas 72 fêmeas bovinas da raça Holandesa Preta e Branca e seus cruzamentos; provenientes da região de Marechal Cândido Rondon -PR. A fim de proporcionar homogeneidade entre os indivíduos constituintes de cada tratamento foi realizada prévia triagem dos animais avaliados pelo presente estudo. Foram selecionadas fêmeas multíparas, apresentando de três a seis parições, e em fase inicial da lactação, até 90 dias do parto. Esses animais foram selecionados pela ausência de mastite clínica e presença da forma subclínica da doença, considerando os resultados do teste de Tamis e California Mastite Teste (CMT), respectivamente.

$O$ teste de Tamis foi realizado antes da primeira ordenha do dia, a partir da coleta dos três primeiros jatos de leite de cada quarto mamário, 
pesquisando-se a presença de grumos, coágulos, pus ou outras alterações sugestivas de mastite clínica. Os animais que apresentaram resultados positivos foram excluídos deste estudo.

O CMT foi realizado de acordo com Schalm e Noorlander (1957), misturando-se igual quantidade de lauril sulfato de sódio a 3\% com leite colhido de cada quarto mamário. O teste foi classificado como: 0 para amostras não reagentes; 1 para aquelas correspondentes a leve formação de gel (escore +), 2 para formação mais espessa de gel com mamilo central (escore ++) e 3 para formação de gel muito espesso aderente ao fundo do recipiente (escore +++ ).

Para as amostras positivas ao CMT, procedeu-se contagem de células somáticas (CCS) e análise microbiológica, realizadas no Departamento de Higiene Veterinária e Saúde Pública da Faculdade de Medicina Veterinária e Zootecnia da Universidade Estadual Paulista, Campus de Botucatu. Esses exames avaliaram amostras de cada quarto mamário separadamente.

Para CCS, adicionou-se conservante Bronopol (2-bromo-2-nitro1,3-propanodiol) às amostras de leite, que foram mantidas em temperatura ambiente até seu processamento. Utilizou-se aparelho eletrônico Somacount 300 (Bentley), e valores maiores ou iguais a 200 mil células somáticas por mililitro de leite foram considerados positivos para mastite subclínica, de acordo com Souza (2005), Ruegg (2008).

A coleta de leite para análise microbiológica foi realizada após as mãos serem lavadas, desinfetadas (álcool 70\%) e enluvadas. As tetas foram lavadas com água, secas com papel toalha e suas extremidades desinfetadas com algodão embebido com álcool $70 \%$.
Foram realizados cultivos microbiológicos de $0,1 \mathrm{~mL}$ de leite em placas de Petri contendo ágar-sangue ovino $5 \%$ e Mac Conkey ágar, incubados a $37^{\circ} \mathrm{C}$. Realizaram-se avaliação das colônias após 24, 48 e 72 horas. As colônias foram submetidas à coloração de Gram, a fim de verificar morfologia bacteriana e característica morfotintorial. Os microrganismos foram repicados para caldo cérebro-coração $(\mathrm{BHI})$ para realização das provas de identificação, segundo Quinn et al. (1994).

Os exames supracitados foram realizados imediatamente antes da formação dos grupos e início dos tratamentos (dia zero), e foram repetidos em cada animal aos sete e 14 dias após o tratamento.

Considerando os resultados apresentados pelo CMT, procedeu-se distribuição aleatória dos animais, por meio de sorteio. Dessa forma, cada tratamento foi constituído por 17 animais, exceto o grupo controle que foi constituído por 16 animais. Aqueles do grupo extrato alcoólico de própolis a $30 \%$, (EAP1) receberam $10 \mathrm{~mL}$ desse extrato por via oral, durante sete dias consecutivos, após cada ordenha. Os animais referente ao grupo EAP2, além do procedimento descrito para o grupo anterior, foram submetidos à $5 \mathrm{~mL}$ EAP para imersão dos tetos, no momento imediatamente anterior e posterior à ordenha; diariamente. Como veículo, utilizou-se $5 \mathrm{~mL}$ de água filtrada e fervida no momento pré-ordenha, e glicerina líquida, em igual volume, após ordenha. O tempo de imersão foi de aproximadamente 30 segundos, alcançando todo comprimento dos tetos. Para os animais constituintes do grupo controle (CA), administrou-se $10 \mathrm{~mL}$ de álcool de cereais (solvente utilizado para a confecção do extrato de própolis), por via oral, durante sete dias consecutivos. Os animais referentes ao grupo controle (CT) foram submetidos ao tratamento 
rotineiramente utilizado pela propriedade (nenhum produto era utilizado, procedia-se limpeza das tetas com água de torneira e secagem com toalha; antes da ordenha).

A própolis utilizada foi proveniente da região de Marechal Cândido Rondon - PR, cuja flora apícola é composta principalmente pelas espécies: Plathymenia foliosa, Hovenia dulcis, Parapiptadenia rigida, Mimosa binucronata e Cordia trichotoma (Lüpke et al., 2009).

Coletou-se a própolis bruta por raspagem, e posteriormente as amostras foram fragmentadas, pesadas e mantidas à temperatura de $-4^{\circ} \mathrm{C}$ até o momento do preparo do extrato alcoólico. Para obtenção do extrato a $30 \%$ utilizou-se álcool de cereais, na proporção peso por peso, onde se pesou tanto a própolis quanto 0 solvente. Este extrato foi acondicionado em frasco âmbar, mantido ao abrigo da luz durante 20 dias consecutivos; procedeu-se a agitação diária do frasco, por trinta segundos, conforme Garcia et al. (2004). Ao término, obteve-se o extrato de própolis por meio de filtração, que foi encaminhado para análises físico-químicas. Determinou-se peso seco, extrato seco, compostos fenólicos (\%), teor de flavonóides em Quercetina (\%), $\mathrm{pH}$ e propriedade antioxidante.

A distribuição da ocorrência de mastite, segundo CMT, nos grupos e momento de avaliação foi avaliada por meio da estatística descritiva envolvendo frequência absoluta e percentual (Zarr, 1999). O estudo do CMT e da CCS segundo os grupos e tetos foi analisado por técnica de variância não paramétrica para o modelo de medidas repetidas em grupos independentes, complementada com os respectivos testes de comparações múltiplas, no nível de $5 \%$ de significância (Zarr, 1999). A indicação da significância foi realizada por meio de letras colocadas ao lado das medidas descritivas (mediana), onde duas medidas seguidas de uma mesma letra minúscula não diferem $(P>0,05)$ quanto aos respectivos grupos fixado o momento de avaliação, e duas medidas seguidas de uma mesma letra maiúscula não diferem $(P>0,05)$ quanto aos respectivos momentos de avaliação dentro do grupo considerado.

\section{RESULTADOS E DISCUSSÃO}

A mastite bovina continua sendo considerada como a principal doença da bovinocultura leiteira, apresentando-se amplamente disseminada nos rebanhos brasileiros. No presente estudo observou-se ocorrência em 71 animais $(98,7 \%)$, com menor prevalência da forma clínica $4(5,3 \%)$ em relação à subclínica 67 (94,7\%). Resultados semelhantes têm sido descritos nos últimos anos. Fontana et al. (2010) verificaram que a mastite subclínica apresentou prevalência de 15 a 40 vezes maior que a forma clínica da doença. Martins et al. (2010) registraram ocorrência de $85,2 \%$, cujo percentual de quartos mamários correspondeu à $65 \%$ e 5,8\% para mastite subclínica e clínica, respectivamente. Da mesma forma, Silva e Cavalcanti (2012) registraram alta ocorrência de mastite subclínica no rebanho avaliado, que variou entre $76 \%$ e $81,6 \%$.

Os animais positivos para o teste de Tamis, no momento anterior à aplicação dos tratamentos, não foram utilizados pelo presente estudo. Porém, este teste foi utilizado para o monitoramento de todos os animais que apresentaram resultados positivos para o CMT, aos sete e 14 dias após a realização dos tratamentos. Embora Fontana et al. (2010) tenham registrado que a mastite clínica usualmente precede à forma clínica da doença, este fato não foi observado pelo presente estudo, uma vez que $100 \%$ dos tetos avaliados permaneceram negativos para 
o teste de Tamis; demonstrando que não houve evolução para a forma clínica da doença, para o período avaliado.

Em relação ao Califórnia Mastite Teste, no momento anterior à aplicação dos tratamentos, registrou-se homogeneidade na frequência e grau de acometimento entre os animais avaliados (Tabela 1).

\begin{tabular}{|c|c|c|c|}
\hline \multirow[b]{2}{*}{ Grupo } & \multicolumn{3}{|c|}{ Momentos de avaliação } \\
\hline & T0 & $\mathrm{T7}$ & T14 \\
\hline \multirow[t]{2}{*}{ Oral } & $3,25 \pm 0,89$ & $3,00 \pm 1,15$ & $2,60 \pm 1,37$ \\
\hline & $4,00(2,00-4,00)$ aA & $3,00(1,00-4,00)$ aA & $2,00(1,00-4,00)$ aA \\
\hline \multirow{2}{*}{$\begin{array}{l}\text { Orale } \\
\text { Imersão }\end{array}$} & $3,25 \pm 0,88$ & $3,62 \pm 1,03$ & $2,81 \pm 1,28$ \\
\hline & $3,50(1,00-4,00)$ aA & $4,00(1,00-6,00)$ aA & $3,50(1,00-4,00)$ aA \\
\hline \multirow[t]{2}{*}{ Álcool } & $3,32 \pm 0,85$ & $3,04 \pm 1,09$ & $2,56 \pm 1,22$ \\
\hline & $4,00(2,00-4,00)$ aA & $3,00(1,00-4,00)$ aA & $2,00(1,00-4,00)$ aA \\
\hline \multirow[t]{2}{*}{ Controle } & $3,46 \pm 0,71$ & $3,30 \pm 0,92$ & $2,84 \pm 1,12$ \\
\hline & $4,00(2,00-4,00)$ aA & $4,00(1,00-4,00)$ aA & $3,00(1,00-4,00)$ aA \\
\hline
\end{tabular}

Letras minús culas: compar sçăo de grupo fixado o momento

Observa-se na Tabela 1 que não foi possível verificar diferença estatística entre os tratamentos, aos sete e 14 dias após a realização dos mesmos. Apesar do CMT ser considerado um exame eficiente e prático para ser executado durante a ordenha, possui caráter subjetivo e dependente da interpretação de quem o realiza. Brito et al. (1997) relataram que sua classificação em escores, pode ocasionar tanto resultados falsos positivos quanto falsos negativos, sendo indicada a CCS como método diagnóstico mais seguro. Dessa forma, foi realizada CCS como exame complementar. As medidas descritivas da CCS, em relação aos grupos avaliados, estão apresentadas na Tabela 2.

A contagem de células somáticas é parâmetro para avaliação da qualidade do leite (Brasil, 2002). Assim como verificado em relação aos resultados do CMT, a diminuição dos valores de CCS foi observada em todos os grupos avaliados, não havendo diferença entre eles.

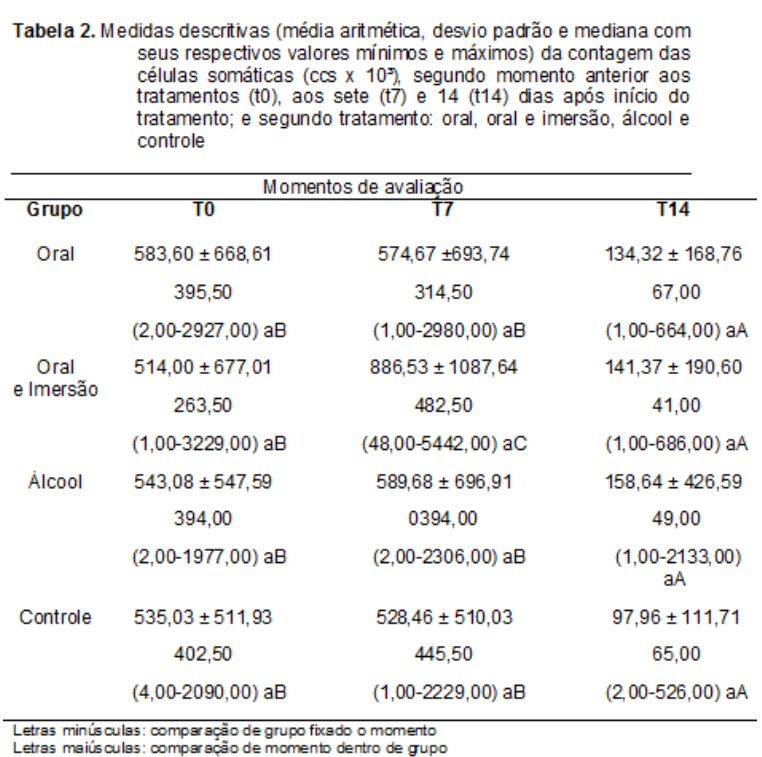

Foram avaliadas 264 amostras de leite. Quatro quartos mamários não foram avaliados devido à atrofia e afuncionalidade decorrente de mastites anteriores. Talvez o número de animais avaliados tenha influenciado sobre a grande variabilidade dos resultados referentes à CCS; uma vez que o grau de comprometimento dos quartos mamários variou de negativo para três cruzes. $O$ aspecto gelatinoso observado pela ação do reagente utilizado no teste CMT, sobre as células somáticas presentes no leite, se dá pela ruptura nuclear e liberação do ácido desoxirribonucleico (DNA) dessas células. Assim, quanto maior o número de células presentes na amostra, mais intensa será essa reação; possibilitando relacionar essas alterações com a contagem de células somáticas da amostra. A correlação desses exames foi demonstrada em bovinos (Brito et al., 1997; Barbosa et al., 2002), bubalinos (Jorge et al., 2005) e caprinos (Silva et al., 2001).

O fato de a mastite bovina ser considerada uma enfermidade multifatorial, podendo ser influenciada por fatores relativos ao homem, ambiente, higiene de ordenha e tipo de comportamento dos ordenhadores na lida com os animais, deve ser considerado. Provavelmente, a presença dos pesquisadores no 
ambiente da ordenha, influenciou 0 comportamento dos ordenhadores, favorecendo a realização das boas práticas de manejo e higiene durante a ordenha. A alta prevalência da mastite relaciona-se às más condições de higiene do ordenhador, bem como dos tetos e úberes das vacas antes, durante e após a ordenha (Oliveira et al., 2009). Boas práticas de manejo favorecem a diminuição de CCS (Silva et al., 2011).

Outro fator que provavelmente influenciou os resultados obtidos pelo presente estudo, diz respeito ao clima. Este experimento foi realizado durante o mês de Dezembro, período chuvoso do ano. Entretanto, após iniciado os tratamentos, o clima melhorou, cessando temporariamente a ocorrência das chuvas na região. Dessa forma, esse fato pode ter sido parcialmente responsável, pela diminuição da CCS nos animais avaliados. Silva e Cavalcanti (2012) avaliaram 2.599 animais e 9.677 amostras de leite, e observaram favorecimento do período chuvoso sobre a ocorrência de mastite nos tetos dos animais. Precipitações elevadas, aliadas às altas temperaturas podem favorecer a incidência de mastite subclínica (Harmon, 1994), pelo aumento da susceptibilidade às infecções bacterianas (Santos, 2004).

Souza (2005) e Ruegg (2008) consideraram valores acima de 200 mil células $/ \mathrm{mL}$, indicativos de mastite subclínica. Fonseca e Santos (2000) admitiram o intervalo de 200 a 400 mil células $/ \mathrm{mL}$. Desta forma, o presente estudo considerou o limite de 200 mil $\mathrm{cel} / \mathrm{mL}$, como limite máximo para animais sadios.

$\mathrm{Em}$ relação às análises microbiológicas, verificou-se que em 174 amostras que apresentaram CCS acima de 200 mil células por $\mathrm{mL}, 150$ delas (86,20\%) apresentaram infecção mamária. Após avaliar 109 quartos mamários, no momento imediatamente anterior ao início do presente estudo, foi registrado crescimento bacteriano em $79,81 \%$ das amostras. Verificou-se a presença de Staphylococcus aureus (42,30\%), Staphylococcus ssp $(20,19 \%)$, Streptococcus agalactiae (19,23\%), Streptococcus uberis $(14,42 \%)$, Streptococcus dysgalactiae (8,65\%) e Corynebacterium bovis $(6,73 \%)$. Os resultados obtidos no presente estudo, corroboram com os resultados observados por Martins et al. (2010), Zanette et al. (2010) e Saeki et al. (2011) que incriminam a infecção bacteriana como causa mais frequente de mastite bovina, principalmente pela ocorrência de Staphylococcus aureus. A alta frequência de Staphylococcus aureus nos casos de mastite pode ser explicada pelo fato de que a pele do úbere e a dos tetos são os principais sítios de localização desses agentes, o que acaba facilitando as infecções por esse microrganismo (Zanette et al., 2010).

Apesar dos animais portadores de mastite clínica não fazerem parte deste estudo, o cultivo das amostras de leite em meio Mac Conkey Agar, foi realizado a fim de certificar a ausência de microrganismos Gram negativos. Dessa forma, como era de se esperar, não foi verificado crescimento bacteriano, em $100 \%$ das amostras avaliadas pelo referido cultivo.

Em relação à análise da própolis, determinou-se peso seco de $121,70 \mathrm{mg} / \mathrm{mL}$ e teor de extrato seco de $13,17 \%$. A instrução normativa $n^{\circ} 03$ (Brasil 2001), estabelece apenas valor mínimo de extrato seco, que corresponde a $11 \%$. Dessa forma, os valores encontrados estão de acordo e acima do limite mínimo exigido para comercialização do produto.

Considerando-se

que a composição química da própolis é extremamente complexa e que pode variar em até 300 componentes, e considerando-se ainda que os compostos fenólicos e flavonóides têm 
sido associados às principais atividades terapêuticas da própolis (Lustosa et al. 2008), optou-se por realizar especificamente essas determinações. $\mathrm{O}$ presente estudo verificou teores de $55,5 \%$ e $1,19 \%$ de compostos fenólicos e flavonóides; respectivamente. $\mathrm{O}$ mínimo de compostos fenólicos exigido é $0,50 \%$ e $0,25 \%$ para os compostos flavonóides (Brasil 2001). Assim, a amostra avaliada, enquadrava-se nos padrões de qualidade exigidos.

Gonsales et al. (2006), verificaram variações entre 0,05 a $0,63 \%$ nos teores de flavonóides em extrato etanóico de própolis a $70 \%$; no estado de São Paulo. Pavanelli et al. (2007), analisaram três tipos de extrato etanólico de própolis coletados em Campo Grande-MS, e encontraram valores médios de $40,15 \%$ para compostos fenólicos e 3,16\% para flavonóides.

Sousa et al. (2007) verificaram o teor de flavonóides totais em amostras provenientes de São Paulo (região de Franca) e Minas Gerais (região de Passo), encontrando média de 0,38 a $0,06 \%$ para São Paulo e entre 0,12 a $2,11 \%$ para Minas Gerais. Essa elevada variabilidade no teor de flavonóides na própolis deve-se provavelmente a diferentes fontes de exsudado vegetal, bem como a localização do apiário.

Em relação ao $\mathrm{pH}$, a amostra de própolis utilizada pelo presente estudo apresentou valor de 5,08; o que também foi observado por Longuini et al. (2007) e Bezerra e Gonçalves (2008). A instrução normativa $n$ ㅇ. 03 não estabelece um parâmetro de qualidade para essa variável (Brasil 2001).

Substâncias flavonóides e compostos fenólicos, presentes nos extratos de própolis, são reconhecidos pela ação antioxidante (Bezerra e Gonçalves 2008). Sousa et al. (2007) registraram essa atividade em amostras provenientes de São Paulo (região de Franca) e Minas Gerais (região de
Passo). Corroborando com esses resultados, o presente estudo, verificou atividade antioxidante do extrato avaliado (EAP a $30 \%$ ), pela solubilidade positiva para acetato de chumbo e ao $\mathrm{NaOH}$. Considerando-se que esta avaliação é apenas qualitativa e não quantitativa, o regulamento técnico de identidade e qualidade da própolis estabelece exigência apenas para positividade da prova, correspondendo ao tempo de reação máximo de 22 segundos (Brasil, 2001).

$O$ efeito antimicrobiano do extrato utilizado pelo presente estudo, foi avaliado previamente, in vitro (Saeki, et al. 2011). Seu efeito antimicrobiano sobre Staphylococcus aureus, demonstrou percentuais de atuação semelhantes aos antimicrobianos comumente utilizados na terapia dessa enfermidade. A sensibilidade dos isolados aos agentes antimicrobianos foi determinada pela técnica de difusão em placas de Ágar Mueller-Hinton, e as drogas utilizadas foram: ampicilina, cefalexina, estreptomicina, ciprofloxacina, gentamicina, norfloxacina e tetraciclina. Para o presente extrato, verificou-se que das 38 amostras de leite avaliadas, que apresentaram crescimento de Staphylococcus aureus, 35 (92,10\%) apresentaram sensibilidade ao extrato de própolis a 30\% (Saeki et al., 2011). Este resultado foi o principal motivador para a continuidade dos estudos in vivo.

Langoni (1996) obteve 90\% de inibição ao Streptococcus agalactiae e $100 \%$ ao Staphylococcus aureus. Loguercio et al. (2006) verificaram sensibilidade ao extrato de própolis, em 94,4\% das colônias de Staphylococcus coagulase-positivos avaliadas.

A ação antimicrobiana da própolis sobre Staphylococcus aureus já havia sido sugerida por Endler et al. (2003); Pinto et al. (2001) e Auricchio et al. (2006). Esta ação se deve à presença de flavonóides, que são solubilizados 
em meio alcoólico, além de outros princípios ativos que sinergicamente contribuem para esta atividade (Auricchio et al.,2006). Segundo TakaisiKikuni e Schilcher (1994), o extrato etanólico de própolis tem capacidade de prevenir a divisão celular, produzir defeitos na estrutura da parede celular, desorganizar o citoplasma; além de causar alteração na membrana citoplasmática e inibir a síntese protéica das bactérias.

A ação química e biológica da própolis depende de diferentes combinações (Franesi, 2007). Scazzocchio et al. (2005), já haviam abordado múltiplos mecanismos sinérgicos envolvidos na atividade antimicrobiana da própolis, indicando interação entre seus constituintes. Assim, apesar do esforço de diferentes grupos de pesquisa nesta área, a farmacodinâmica da própolis ainda não foi completamente elucidada. Apesar disto, e a partir dos resultados obtidos previamente pela avaliação in vitro, o extrato alcoólico de própolis a $30 \%$ ainda pode representar um importante adjuvante para o controle da mastite subclínica, porém exige adicionais ensaios clínicos. Talvez alterando-se a via de administração, e aumentando o tempo de avaliação, os benefícios do uso do extrato de própolis possam ser demonstrados.

\section{CONCLUSÃO}

Para as condições do presente estudo, o extrato alcoólico de própolis a $30 \%$ não apresentou benefícios para o controle da mastite subclínica bovina.

\section{AGRADECIMENTOS}

À Fundação de Amparo à Pesquisa do Estado de São Paulo (FAPESP) pelo apoio financeiro. Ao Senhor Romeu Hepp, pela cedência dos animais e instalações.

\section{NOTAS INFORMATIVAS}

Ética em experimentação animal aprovado pela Câmara de Ética e Experimentação Animal da Faculdade de Medicina Veterinária e Zootecnia, UNESP - Botucatu, (Protocolo no 103/2007 CEEA).

\section{REFERÊNCIAS}

ANDRADE, U. V. C. Potencial antibacteriano do extrato hidrossolúvel de própolis obtido por hidrólise alcalina para a inibição de cultivos de Staphylococcus aureus e higienização de pré e pós - imersão de tetos de vacas leiteiras. 2010. Curitiba. $85 \mathrm{f}$. Tese (Doutorado em Tecnologia de Alimentos) Curso de Pós-Graduação em Tecnologia de Alimentos, Universidade Federal do Paraná.

ARAÚJO, K. C. S.; MARCUCCI, M. C. Efeito sinergístico da própolis tipificada contra Enterococcus faecalis. Revista Pesquisa e Inovação Farmacêutica, v.3, n.1, p.9-14, 2011.

AURICCHIO M. T.; BUGNO, A., ALMODÓVAR, A. A. B., et al. Avaliação da atividade antimicrobiana de preparações de própolis comercializadas na cidade de São Paulo. Revista do Instituto Adolfo Lutz, v.65, n.3, p.209-212, 2006.

BARBOSA, M. H.; ZUFFI, F. B.; MARUXO, H. B., et al. Therapeutic properties of propolis for treatment of skin lesions. Acta Paulista de Enfermagem, v.22, n.3, p.318-22, 2009.

BEZERRA, A.C.A.; GONÇALVES, G.M.S. Avaliação da ação antioxidante de substâncias ativas cosméticas destinadas à prevenção do fotoenvelhecimento cutâneo. IN: ENCONTRO DE INICIAÇÃO CIENTÍFICA DA PONTIFICIA UNIVERSIDADE CATÓLICA, XIII., 2008. Rio de Janeiro. Anais... Rio de Janeiro: PONTIFICIA UNIVERSIDADE CATÓLICA. CD-ROM. IC07123.

BORGES, C. H. F.; ALMEIDA, D. A.; FRAGIORGE; E. J. Atividade antibacteriana e antifúngica de diferentes concentrações de extratos hidroalcoólicos de própolis (EHP) em linguiça frescal suína. FAZU em Revista, n.6, p.53-82, 2009.

BRASIL. Ministério de Agricultura e do Abastecimento. Instrução normativa N. ${ }^{\circ} 3$, de 19 
de janeiro de 2001. Diário Oficial da União, Brasília, D.F. 23 de jan 2001, Seção 1, p.18-23.

BRASIL. Ministério de Agricultura e do Abastecimento. Instrução normativa $n^{0} 51$ de 18 de setembro de 2002. Regulamentos técnicos de produção, identidade, qualidade coleta e transporte de leite. Diário Oficial da União, Brasília, D. F. Secção 1, p.23-57.

BRITO, J. R. F.; CALDEIRA, G. A. V.; VERNEQUE, R. S.; BRITO, M. A. V. Sensibilidade e especificidade do Califórnia Mastitis Test como recurso diagnóstico da mastite sub-clínica em relação à contagem de células somáticas. Pesquisa Veterinária Brasileira, v.17, n.2, p.49-53, 1997.

CABRAL, I. S. R.; OLDONI, T. L. C.;PRADO, A. et al. Composição fenólica, atividade antibacteriana e antioxidante da própolis vermelha brasileira. Química Nova, v.32, n.6, 2009.

COELHO, M. de S.; SILVA, J.H.V. da, OLIVEIRA,E.R.A. de, et al. A própolis e sua utilização em animais de produção. Arquivos de Zootecnia, v.59, p.95-112, 2010.

ENDLER, A. L.; OLIVEIRA, S. C.; AMORIM, C. A., et al. Teste de eficácia da própolis no combate a bactérias patogênicas das vias respiratórias. Ciências Biológicas e da Saúde, v.9, n.2, p.17-20, 2003.

FARNESI A.P. Efeitos da própolis de abelhas africanizadas e meliponíneos em microrganismos. 2007. Ribeirão Preto, 89f. Dissertação de Mestrado,Curso de PósGraduação em Ciências, Universidade Estadual de São Paulo.

FISCHER, G.; HÜBNER, S.O.; VARGAS, G.D., et al. Imunomodulação pela própolis. Arquivos do Instituto Biológico, v.75, n.2, p.247-253, 2008.

FONSECA, L. F. L.; SANTOS, M. V. Qualidade do leite e controle de mastite. São Paulo: Lemos Editorial, 2000. 175p.

FONTANA, V.L.D.S.; GIANNINI, M.J.S.M.; LEITE, C.Q.F., et al. Etiologia da mastite bovina subclínica, sensibilidade dos agentes às drogas antimicrobianas e detecção do gene da $\beta$ lactamase em Staphylococcus aureus.

Veterinária e Zootecnia, v.17, n.4, p.552-559, 2010.
HARMON, R. J. Phisiology of mastitis and factors affecting somatic cell counts. Journal of Diary Science, v.77, n.7, p.2103-2112, 1994

JORGE, A. M.; ANDRIGHETTO, C.; STRAZZA, M. R.B., et al. Correlação entre o Califórnia Mastitis Test (CMT) e a contagem de células somáticas (CCS) do leite de búfalas Murrah. Revista Brasileira de Zootecnia, v.34, n.6, p.2039-2045, 2005.

LANGONI, H.; DOMINGUES, P.F.; SILVIA, R.F., et al. Prototheca zopfii como agente de mastite bovina: clínica e terapêutica. Arquivo Brasileiro de Medicina Veterinária e Zootecnia, n.47, p.727-752, 1995

LANGONI ,H.; DOMINGUES, P.F.; FUNARI C.J., et al. Efeito antimicrobiano in vitro da própolis. Arquivo Brasileiro Medicina Veterinatia Zootecnia, n.48, p.227-229, 1996.

LOGUERCIO, A. P.; GROFF, A. C. M.; WITT, N. M., et al. Atividade in vitro do extrato de própolis contra agentes bacterianos da mastite bovina. Pesquisa Agropecuária Brasileira, v.41, n.2, 2006.

LONGHINI, R.; RASKSA, S. M.; OLIVEIRA, A. C. P., et al. Obtenção de extratos de própolis sob diferentes condições e avaliação de sua atividade antifúngica. Revista Brasileira de Farmacognosia, v.17, n 3, 2007.

LÜPKE, C. J.; GARCIA, R.C.; CHAMBÓ, E.D., et al. Plantas apícolas e análise polínica de méis de Apis mellifera, na região oeste do Paraná. In: CONGRESSO BRASILEIRO DE ZOOTECNIA, IXX., 2009. São Paulo. Anais... São Paulo. p 91 100.

LUSTOSA, S. R.; GALINDO, A.B.; NUNES, L. C. C., et al. Própolis: atualizações sobre a química e a farmacologia. Revista Brasileira de Farmacognosia, v.18, n.3, p.447-454, 2008.

MARTINS, R. P.; SILVA, J. A. G.; NAKAZATO, L., et al. Prevalência e etiologia infecciosa da mastite bovina na microrregião de Cuiabá, MT. Ciência Animal Brasileira, v.11, n.1, p.181187, 2010.

MULI, E. M.; MAINGI, J. M. Antibacterial activity of Apis mellifera L. propolis collected in three regions of Kenya. The Journal of Venomous Animals and Toxins including Tropical Diseases, v.13, n.3, 2007.

OLIVEIRA, A. A.; MELO, C.B., AZEVEDO, H.C. Diagnóstico e determinação microbiológica da 
mastite em rebanhos bovinos leiteiros nos tabuleiros costeiros de Sergipe. Ciência Animal Brasileira, v.10, n.1, p.226-230, 2009.

ÖZDEMIR, A. R.; ÇANDIR, E.E.;

KAPLANKIRAN, M. et al. The effects of ethanoldissolved propolis on the storage of grapefruit cv. Star Ruby. Turkish Journal of Agriculture and Forestry, v.34, p.155-162, 2010.

PAVANELLI, D. M.; GALINDO JÚNIOR, J. B.; BANDEIRA, M. C. E. Avaliação qualitativa de extratos de própolis do cerrado

Sulmatogrossense. In: REUNIÃO ANUAL DA SOCIEDADE BRASILEIRA DE QUÍMICA , XXX, 2007, Águas de Lindóia. Anais... Águas de Lindóia, 2007, p 1-2.

PINTO, M. S.; FARIA, J. E.; MESSAGE, D., et al. Efeito de extratos de própolis verde sobre bactérias patogênicas isoladas do leite de vacas com mastite. Brazilian Journal of Veteterinary Researsch Animal Science, v.38, n.6, p.278283, 2001.

QUINN, P. J.; CARTER, M. E.; MARKEY B. K., et al. Mastitis, In: Clinical Veterinary

Microbiology. London: Mosby-Year Book Europe Ltd, 1994, p. 35-49.

RUEGG, P. L.; PANTO, J. A.; APPARAO, D. Treatment of subclinical mastitis infections. In: CURSOS NOVOS ENFOQUES NA PRODUÇÃO E REPRODUÇÃO DE BOVINOS, XII., 2008. Uberlandia. Anais... Uberlandia: 2008, p.50-56.

SAEKI, E.K.; MELLO-PEIXOTO, E.C.T.; MATSUMOTO, L.S., et al. Mastite bovina por Staphylococcus aureus: sensibilidade às drogas antimicrobianas e ao extrato alcoólico de própolis. Acta Veterinária Basílica, v.5, n.3, p.284-290, 2011.

SANTOS, M. V. In: O compromisso com a qualidade do leite no Brasil. Passo Fundo: Universidade de Passo Fundo: UPF, p.38-55, 2004.

SCAZZOCCHIO, F.; DÁURIA, F. D. D.; ALESSANDRINI D. V., et al. Multifactorial aspects of antimicrobial activity of propolis. Microbiology Research, v.4, n.161, p.327-333, 2006.

SCHALM, O.W.; NOORLANDER, D.D. Experiments and observations leading to development of the California Mastitis Test. Journal Animal Veterinary Medical Association, v.130, p.199 -204, 1957.
SILVA, A. M., CAVALCANTI, E. T. S. Casos de mastite subclínica em vacas lactantes da raça girolanda no período seco e chuvoso do ano, na região litoral do Rio Grande do Norte. Nucleus Animalium, v.4, n.1, p.01-06, 2012.

SILVA, P. D. L.; PAIVA, A. D.; RANGEL, A. H. N., et al. Influência das boas práticas de ordenha e da ordem de parto sobre a composição e contagem de células somáticas (CCS) do leite bovino. Revista Verde de Agroecologia e Desenvolvimento Sustentável, v.6, n.3, p.01-06, 2011.

SILVA, E. R.; ARAÚJO, A. M.; ALVES, F. S., et al. Associação entre California Mastitis Test e a Contagem de Células Somáticas na avaliação da saúde da glândula mamária caprina.

Brazilian Journal Veterinary Research Animal Science, v.38, n.1, p.46-48, 2001.

SOUSA, J. P.B.; FURTADO, N. A. J. C.; JORGE, R., et al. Perfis físico-químico e cromatográfico de amostras de própolis produzidas nas microrregiões de Franca (SP) e Passos (MG), Brasil. Revista Brasileira de Farmacognosia, v.17, n.1, 2007.

SOUZA, G. N. Mastite, contagem de células somáticas e os novos parâmetros para comercialização do leite cru no Brasil. Circular Técnico 70. Embrapa Gado de Leite: MG. 2005.

SOUTO, L. I. M.; SAKATA, S. T.; MINIGAWA, C. Y., et al. Qualidade do leite cru produzido em propriedades do estado de São Paulo, Brasil. Veterinária e Zootecnia, v.16, n.3, p.491-499, 2009.

TAKAISI-KIKUNI, N.B., SCHILCHER. H. Electron microscopic and microcalorimetric investigations of the possible mechanism of the antibacterial action of a defined propolis provenance. Planta Medicinal, v.60, p.222-227, 1994.

ZANETTE, E.; SCAPIN, D.; ROSSI E. M. Suscetibilidade antimicrobiana de Staphylococcus aureus isolados de amostras de leite de bovinos com suspeita de mastite. Unoesc \& Ciência - ACBS, v.1, n.1, p.65-70, 2010.

ZARR J.H. 1999. Bioestatistical Analysis. $4^{\text {th }}$ ed. Pretince Hall, New Jersey. 663p. 